\section{Stop government picking professors}

A September decree by the Italian government aims to recruit leading university professors through an unprecedented and highly questionable procedure. On behalf of Group 2003 (see www.gruppo2003.org), I urge the Italian government to withdraw these resolutions, which breach the academic freedom of the country's scientists and threaten the future of Italian science.

According to the ruling, the prime minister will appoint the chairs of the recruiting panels in different research areas. Each panel comprises only the chair (nominated by the government) and two other members, both chosen by the chair.

This government-controlled university appointment procedure is intended to replace the peer-review methods that are standard in academia worldwide. To our knowledge, it would be the first such system to operate in a democratic country.

Luigi Nicolais University of Naples Federico II, Naples, Italy. nicolais@unina.it

\section{Trump: renewables for self-sufficiency}

US president-elect Donald Trump hopes to achieve energy independence for his country. But even sustaining current energy production will be hard, given that US production of 'tight' oil - extracted from shale rock using fracking - is almost 20\% below its March 2015 peak, and shale-gas production is $5 \%$ below its February 2016 peak.

In August 2016, the United States imported 8 million barrels of crude oil per day, or $48 \%$ of its crude-oil requirements. Tight oil currently accounts for roughly half of US oil, so its production would need to almost triple to replace current imports. This would escalate drilling rates and rapidly exhaust core supply areas, setting the stage for a medium-term production collapse and radically higher prices. Coupled with a comparably aggressive ramp-up of shale-gas production, this increased activity would compound environmental and human-health risks (see, for example, M. Finkel Nature 540, 39; 2016).

We agree with renewables specialist Daniel Kammen that low-carbon alternatives such as wind and solar are the way to go, particularly because job growth and return on investment should be more robust than those from carbon-based energy (see Nature http://doi.org/bs58; 2016).

Seth B. C. Shonkoff ${ }^{\star} P S E$ Healthy Energy, Oakland, California, USA. sshonkoff@psehealthyenergy.org ${ }^{\star}$ On behalf of 7 correspondents (see go.nature.com/2hkumhi for full list).

\section{Trump: time to seize environmental gains}

The United States has led the global environmental movement since the 1970s, albeit intermittently. If it withdraws support for multilateral treaties under President Trump, the environment will not be doomed.

China, for example, could step into the lead (see D. Victor Nature 539,$495 ; 2016)$. China is committed to the Convention on Biological Diversity, which the United States has still not ratified, and to many other international environmental treaties (F. Wu J. Chin. Polit. Sci. 14, 383-406; 2009). If other countries support China, environmental gains can continue - irrespective of a weakened US contribution.

A Trump government that is less concerned about the environment could create space for strengthened independent initiatives, such as commitments to sustainability, by subnational units of government, cities, companies and community groups (N. Lutsey and D. Sperling Energy Policy 36, 673-685; 2008).

And if Trump's promised trade protectionism occurs, scientists could help to shape policies that safeguard the environment such as by restricting imports from regions that do not uphold good environmental practices. Duan Biggs ${ }^{\star}$ Griffith University, Nathan, Queensland, Australia. d.biggs@uq.edu.au ${ }^{*}$ On behalf of 4 correspondents (see go.nature.com/2gfd7kifor full list).

\section{Diversity is future for genetic analysis}

The Population Architecture using Genomics and Epidemiology (PAGE) study, to which I contribute, is overcoming some of the technical challenges of multi-ethnic genomic analyses (see A. B. Popejoy and S. M. Fullerton Nature 538, 161-164; 2016). It is yielding findings that are unattainable for homogeneous populations.

PAGE, funded by the US National Institutes of Health, uses genome-wide analyses of 50,000 phenotyped participants of mainly Hispanic and African ancestry. We aggregate results across several studies: for example, two are multi-ethnic, one involves only women and one is designed to address underrepresentation of Hispanic people (see go.nature.com/2hity $2 \mathrm{j}$ ).

We collaborated with other initiatives, including the Consortium on Asthma among African-ancestry Populations in the Americas, to develop an unbiased genotyping array for use across all major continental populations (www.pagestudy. org/mega). Statistical tools such as SUGEN (D. Y. Lin et al. Am. J. Hum. Genet. 95, 675-688; 2014) and GENESIS (M. P. Conomos et al. Am. J. Hum. Genet. 98, 127-148; 2016) can account for the admixed ancestry of individuals (a significant factor in almost every US minority), and for cohorts that include many ancestries.

Leveraging sample diversity in these and other ways has maximized the power of our genetic analyses.
Christopher S. Carlson Fred Hutchinson Cancer Research Center, Seattle, Washington, USA. ccarlson@fhcrc.org

\section{Sustainable fisheries need reserves}

Indigenous people such as the Maori and other Polynesians traditionally maintain that the mauri (life force) of the ocean must be protected if humans are to prosper. This is echoed by the United Nations Convention on the Law of the Sea, which permits only sustainable fishing activity and aims to protect marine biodiversity. However, far too few governments are honouring that commitment.

Simply making fisheries responsible for conserving nature (R. Hilborn Nature 535, 224-226; 2016) may not work because of the conflict of interest with maximizing catch. In our view, fisheries should instead be under the jurisdiction of agencies whose primary responsibility is to protect biodiversity. Conservation is already using simpler, easyto-manage and cost-effective methods to protect fisheries, and more than $90 \%$ of marine protected areas (MPAs) allow fishing that supports sustainable fisheries (M. J. Costello and B. Ballantine Trends Ecol. Evol. 30, 507-509; 2015).

Integrating fisheries into conservation agencies would prioritize the health of ecosystems, for example by establishing marine reserves (no-take MPAs). Very large examples of such reserves have recently been created by indigenous Pacific islanders in Palau and Kiribati (see also Nature 539, 13-14; 2016). These safe havens can provide stock and spillover for fisheries, as well as baselines for unfished ecosystems and other benefits.

Mark John Costello ${ }^{\star}$ University of Auckland, New Zealand. m.costello@auckland.ac.nz

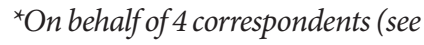
go.nature.com/2gollxm for full list). 